\title{
PENGARUH HARGA, PROMOSI, BUKTI FISIK, DAN KUALITAS LAYANAN TERHADAP MINAT BERKUNJUNG KE DYNASTY WATER WORLD GRESIK
}

\author{
VENNY KARTIKA SARI \\ Progam Studi Manajemen \\ Fakultas Ekonomi- Universitas Muhammadiyah Gresik \\ Jl. Sumatra No. 101 GKB Gresik 61121 Jawa Timur Indonesia
}

\begin{abstract}
ABSTRAK
Penelitian ini bertujuan untuk menganalisis pengaruh harga, promosi, bukti fisik, dan kualitas layanan terhadap minat berkunjung ke Dynasty Water World Gresik. Adapun sampel penelitian ini terdiri dari 100 responden. Variabel independen dalam penelitian ini adalah harga, promosi, bukti fisik, dan kualitas layanan, sedangkan variabel dependennya adalah minat berkunjung ke Dynasty Water World Gresik. Teknik analisis data yang digunakan adalah regresi linier berganda dengan bantuan program SPSS. Hasil penelitian menunjukkan bahwa variabel promosi, bukti fisik, dan kualitas layanan berpengaruh secara parsial terhadap minat berkunjung, sedangkan variabel harga dinyatakan tidak memiliki pengaruh yang signifikan terhadap minat berkunjung berkunjung ke Dynasty Water World Gresik.
\end{abstract}

Kata kunci : Harga, Promosi, Bukti Fisik, Kualitas Layanan, Minat Berkunjung

\section{PENDAHULUAN}

Semakin berkembangnya perekonomian juga makin meningkatkan persaingan diantara para pelakunya, salah satunya adalah perusahaan. Karena perusahaan memiliki tujuan utama memaksimalkan laba, maka perusahaan berlomba- lomba untuk memperbaiki operasionalnya, salah satunya adalah aspek pemasaran. Aspek pemasaran diketahui sebagai suatu pilar utama perusahaan dalam mencapai tujuannya, yakni memaksimalkan laba. Pemasaran sering digambarkan sebagai seni menjual produk, tetapi orang heran ketika mereka mendengar bahwa bagian yang paling penting dari pemasaran adalah bukan penjual (Kotler dan Amstrong, 2014; 125).

Agar dapat berjalan sesuai dengan tujuan, maka kegiatan pemasaran juga perlu dikelola dengan baik, hal ini dikenal dengan istilah manajemen pemasaran. Konsep bauran pemasaran (Tjiptono, 2011;30) mendefinisikan bauran pemasaran (Marketing Mix) adalah seperangkat alat pemasaran yang digunakan perusahaan untuk terus-menerus mencapai tujuan pemasarannya di pasar sasaran. Menurut Tjiptono (2011;39) bauran pemasaran jasa adalah terdiri dari yaitu Product (produk), Price (harga), Place (lokasi), Promotion (promosi), People or Participant (penyedia jasa/orang), Process (proses jasa),dan Physical Evidence (bukti fisik) .

Dynasty Water World merupakan perusahaan yang bergerak dibidang.Pariwisata berupa wahana bermain air yang didirikan pada
Bulan Maret 2016, dari konteks tersebut, Dysnasty Water World dapat dikategorikan sebagai perusahaan jasa. Menurut Kotler (2009; 386) Perusahaan jasa merupakan perusahan yang setiap tindakan atau kinerja yang ditawarkan oleh satu pihak ke pihak lain yang secara prinsip tidak berwujud dan tidak menyebabkan perpindahan kepemilikan. Sebagai perusahaan, tentu saja Dynasty Water World juga melakukan optimalisasi aspek pemasarannya dengan memperhatikan bauran pemasaran jasa seperti yang telah diuraikan di atas. Terlebih karena Dynasty Water World masih terbilang sebagai wahana rekreasi yang masih baru hadir di tengah-tengah Kota Gresik dan sekitarnya. Pada mulanya Dynasty Water World mematok harga Rp 50.000,- untuk weekday dan Rp 75.000,- untuk weekend namun pada Bulan Juni manajemen menetapkan harga tiket masuk untuk hari biasa Rp 25.000 dan Rp 45.000 untuk hari minggu, hari libur dan hari besar, dengan rata-rata jumlah pengunjung di hari biasa adalah 300 pengunjung dan 800 pengunjung di hari libur atau hari besar, maka pendapatan rata-rata Dynasty Water World per bulan adalah Rp 280.000.000,-. s/d Rp 300.000.000,- Angka tersebut cukup tinggi untuk ukuran UKM yang belum genap setahun menjalankan usahanya. Data omzet pendapatan per bulan Dynasty Water World dapat ditunjukan pada gambar di bawah ini : 
Gambar 1.1 Data Omzet Maret - Agustus Tahun 2016

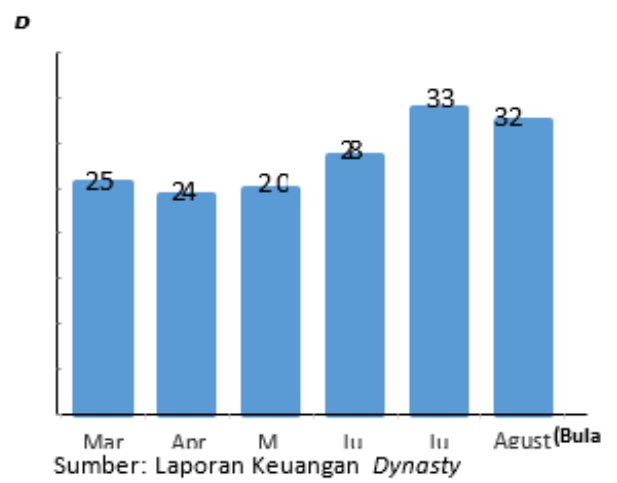

Data di atas menunjukkan bahwa pada Bulan Maret 2016 yakni awal dibuka, Dynasty Water World mampu meraup pendapatan sebesar Rp 255.000.000 kemudian pada Bulan April turun ke angka Rp 243.000.000 dan selanjutnya pendapatan pada Bulan Mei sebesar Rp 249.750.000. setelah dilakukan perubahan harga yakni dimulai pada Bulan Juni, omzet yang diperoleh mengalami peningkatan yang signifikan, yakni Rp 286.750.000. kemudian untuk Bulan Juli dan Agustus, omzet perusahaan mencapai Rp 339.000.000 dan Rp 328.900.000.

Sebagai perusahaan yang baru saja berjalan, Dynasty Water World harus giat melakukan kegiatan promosi. Promosi yang dilakukan melalui sosial media, serta tambahan fasilitas di hari tertentu seperti event mandi busa dan live music di hari libur dan hari besar. Dynasty Water World juga memiliki keunggulan dari segi fisik, yakni wahana yang lebih luas yang terdiri dari wahana air, wahana bermain anak, wahana untuk foto dan acara seperti wedding, dan cafe. Salah satu aspek yang mendasar adalah harga. Engel $(2008 ; 44)$ mendefinisikan harga sebagai sejumlah uang (ditambah beberapa produk) yang dibutuhkan untuk mendapatkan sejumlah kombinasi dari produk dan pelayanannya. Para pelanggan di era modern ini cenderung lebih cerdas, mereka tidak lagi memandang suatu produk berdasarkan harga yang murah, mereka mengetahui esensi harga, sehingga ungkapan "ada harga ada kualitas".

Aspek selanjutnya yang dapat dipertimbangkan oleh perusahaan adalah bentuk fisik yang ada di wahana tersebut. jika wujud fisik memiliki daya tarik yang menjadi ciri khas sebuah tempat, maka konsumen cenderung penasaran dan ingin berkunjung. Setelah semuanya dipertimbangkan dengan baik, maka langkah akhir perusahaan adalah berusaha menjadi pelayan yang baik bagi konsumen. Menurut Alma (2014; 61) pengertian physical evidence (bukti fisik) merupakan suatu hal yang secara turut mempengaruhi keputusan konsumen untuk membeli dan menggunakan produk jasa yang di tawarkan. Unsur-unsur yang termasuk didalam sarana fisik antara lain lingkungan fisik, dalam hal ini bangunan fisik, peralatan, perlengkapan, logo, warna dan barang-barang lainya yang disatukan dengan service yang diberikan seperti tiket, sampul, label, dan lain sebaginya.

Aspek terakhir yang harus diperhatikan adalah kualitas layanan. Layanan pelanggan meliputi aktivitas untuk memberikan kegunaan waktu dan tempat, termasuk pelayanan pratransaksi, saat transaksi, dan pascatransaksi. Kegiatan pratransaksi akan turut mempengaruhi kegiatan saat dan pascatransaksi. Oleh karena itu, kegiatan pendahuluannya harus dilakukan sebaik mungkin sehingga konsumen memberikan respons yang positif dan menunjukkan loyalitas yang tinggi (Tjiptono, 2011; 42).

Omset yang mengalami perubahan saat Dynasty Water World memutuskan untuk melakukan perubahan harga tiket masuk, menambahkan wahana, serta perubahan strategi promosi dengan layanan yang makin meningkat. Selain dampak secara parsial, peneliti juga tertarik untuk menganalisa apakah bauran aspek tersebut juga memiliki dampak yang kuat terhadap minat berkunjung masyarakat Gresik ke Dynasty Water World dan dimana minat berkunjung sangat berpengaruh terhadap harga,promosi,bukti fisik dan kualitas layanan. Oleh karena itu,, maka peneliti tertarik untuk mengambil judul "Pengaruh Harga, Promosi, Bukti Fisik, dan Kualitas Layanan Terhadap Minat Berkunjung ke Dynasty Water World Gresik”.

\section{Landasan Teori \\ Harga (Price)}

Engel (2008; 44) mendefinisikan harga sebagai sejumlah uang (ditambah beberapa produk) yang dibutuhkan untuk mendapatkan sejumlah kombinasi dari produk dan pelayanannya. Dari definisi di atas dapat diketahui bahwa harga yang dibayar oleh pembeli sudah termasuk layanan yang diberikan oleh penjual. Banyak perusahaan mengadakan pendekatan terhadap penentuan harga berdasarkan tujuan yang hendak dicapainya. Adapun tujuan tersebut dapat berupa meningkatkan penjualan, mempertahankan market share, mempertahankan stabilitas harga, mencapai laba maksimum dan sebagainya. 


\section{Promosi (Promotion)}

Suatu produk yang memiliki kualitas tinggi dan harga yang murah, namun tidak dikenal oleh pasar maka segala kelebihan atribut yang dimiliki produk tersebut menjadi sia-sia. Usaha untuk mengenalkan produk kepada pasar yaitu dilakukan strategi promosi. Konsep yang dipakai untuk mengenalkan produk yaitu promotion mix, kegiatan- kegiatan yang mengkombinasikan keunggulan produk dan menunjuk konsumen untuk membeli (Swastha dan Handoko, 2014; 28).

\section{Bukti Fisik ( Physical Evidence)}

Menurut Alma $(2013 ; 61)$ pengertian physical evidence (bukti fisik) merupakan suatu hal yang secara turut mempengaruhi keputusan konsumen untuk membeli dan menggunakan produk jasa yang ditawarkan. Unsur-unsur yang termasuk didalam sarana fisik antara lain lingkungan fisik, dalam hal ini bangunan fisik, peralatan, perlengkapan, logo, warna dan barang-barang lainya yang disatukan dengan service yang diberikan seperti tiket, sampul, label, dan lain sebaginya. Alma (2013; 63) mengemukakan bahwa perusahaan melalui tenaga pemasaranya menggunakan tiga cara dalam mengelola bukti fisik yang strategis.

\section{Kualitas Layanan}

Menurut Tjiptono $(2011 ; 42)$ dalam sektor jasa, layanan pelanggan dapat diartikan sebagai kualitas total jasa yang dipersepsikan oleh pelanggan. Layanan pelanggan pada pemasaran jasa lebih dilihat sebagai hasil (outcome) dari kegiatan distribusi dan logistik, di mana pelayanan diberikan kepada konsumen untuk mencapai kepuasan. Layanan pelanggan meliputi aktivitas untuk memberikan kegunaan waktu dan tempat, termasuk pelayanan pratransaksi, saat transaksi, dan pascatransaksi. Kegiatan pratransaksi akan turut mempengaruhi kegiatan saat dan pascatransaksi.

\section{Minat Berkunjung}

Menurut Kotler dan Keller (2013; 183), mendefinisikan minat berkunjung adalah sebuah perilaku konsumen dimana konsumen mempunyai keinginan dalam berkunjung ke suatu tempat, berdasarkan pengalaman dalam memilih, menggunakan dan mengkonsumsi atau bahkan menginginkan suatu produk. FaktorFaktor yang mempengaruhi minat beli konsumen berhubungan dengan perasaan dan emosi, bila seseorang merasa minat membeli, ketidakpuasan biasanya menghilangkan minat.

\section{Gambar 1.1 Rerangka Berpikir}

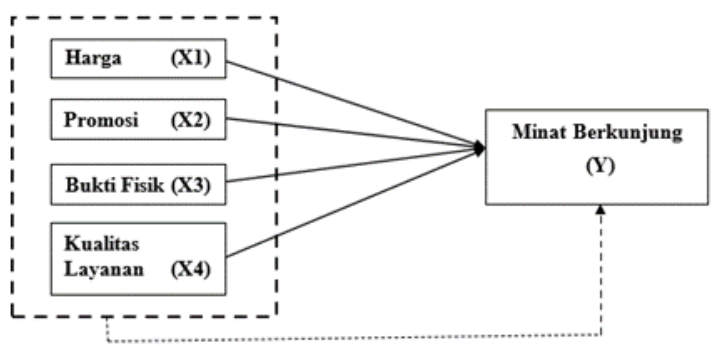

\section{METODE PENELITIAN}

Menurut Indrianto dan Supomo (2012; 92) populasi adalah sekelompok orang, kejadian atau segala sesuatu yang mempunyai karakteristik tertentu. Populasi yang digunakan dalam penelitian ini adalah pengunjung Dynasty Water World Gresik.Sampel adalah bagian dari jumlah dan karakteristik yang dimiliki oleh populasi (Indiantoro dan Supomo; 2012; 92). Teknik pengambilan sampel dalam penelitian ini dengan menggunakan Purposive Sampling. menurut (Indiantoro dan Supomo; 2012; 94) purposive sampling adalah pengambilan anggota sampel dari populasi berdasarkan kriteria tertentu. Adapun kriteria yang dimaksud adalah:

1. Responden merupakan pengunjung Dynasty Water World Gresik.

2. Responden berusia minimal 17 tahun

3. Pendidikan terakhir responden minimal SMP

Ukuran sampel ditentukan dengan kriteria Ferdinand dalam Arianto (2013; 299) yang mengungkapkan bahwa dalam penelitian multivariate (termasuk yang menggunakan analisis regresi multivariate) besarnya sampel ditentukan sebanyak 25 kali variabel independen.

HASIL PENELITIAN

Uji Validitas

1. Variabel Harga (X1)

Tabel 1.1 Hasil Uji Validitas Instrumen Pertanyaan

\begin{tabular}{|l|l|l|l|}
\hline $\begin{array}{l}\text { Butir } \\
\text { Pertanyaa } \\
\text { n }\end{array}$ & $\begin{array}{l}\mathbf{r} \text { Hitun } \\
\text { g }\end{array}$ & $\begin{array}{l}\text { r } \\
\text { Tabe } \\
\mathbf{l}\end{array}$ & $\begin{array}{l}\text { Keteranga } \\
\mathbf{n}\end{array}$ \\
\hline X1.1 & 0,864 & 0,195 & Valid \\
\hline X1.2 & 0,873 & 0,195 & Valid \\
\hline X1.3 & 0,934 & 0,195 & Valid \\
\hline
\end{tabular}


2. Variabel Promosi (X2)

Tabel 1.2 Hasil Uji Validitas Instrumen

Pertanyaan Variabel Promosi (X2)

\begin{tabular}{|c|c|c|c|}
\hline $\begin{array}{l}\text { Butir } \\
\text { Pertanyaan }\end{array}$ & $\begin{array}{l}\mathbf{r} \\
\text { Hitung }\end{array}$ & $\begin{array}{l}\mathbf{r} \\
\text { Tabel }\end{array}$ & Keterangan \\
\hline $\mathrm{X} 2.1$ & 0,926 & 0,195 & Valid \\
\hline $\mathrm{X} 2.2$ & 0,918 & 0,195 & Valid \\
\hline $\mathrm{X} 2.3$ & 0,745 & 0,195 & Valid \\
\hline
\end{tabular}

3. Variabel Bukti Fisik (X3)

Tabel 1.3 Hasil Uji Validitas Instrumen Pertanyaan Variabel Bukti Fisik (X3)

\begin{tabular}{|l|l|l|l|}
\hline $\begin{array}{l}\text { Butir } \\
\text { Pertanyaan }\end{array}$ & $\begin{array}{l}\text { H } \\
\text { Hitung }\end{array}$ & $\begin{array}{l}\text { r } \\
\text { Tabel }\end{array}$ & Keterangan \\
\hline X3.1 & 0,645 & 0,195 & Valid \\
\hline X3.2 & 0,877 & 0,195 & Valid \\
\hline X3.3 & 0,799 & 0,195 & Valid \\
\hline
\end{tabular}

4. Variabel Kualitas Layanan (X4)

Tabel 1.4 Hasil Uji Validitas Instrumen

Pertanyaan Variabel Kualitas Layanan (X4)

\begin{tabular}{|l|l|l|l|}
\hline $\begin{array}{l}\text { Butir } \\
\text { Pertanyaan }\end{array}$ & $\begin{array}{l}\text { H } \\
\text { Hitung }\end{array}$ & $\begin{array}{l}\text { T } \\
\text { Tabel }\end{array}$ & Keterangan \\
\hline X4.1 & 0,895 & 0,195 & Valid \\
\hline X4.2 & 0,933 & 0,195 & Valid \\
\hline
\end{tabular}

Tabel 1.5

Hasil Uji Validitas Instrumen Pertanyaan Variabel Minat Berkunjung (Y)

\begin{tabular}{|l|l|l|l|}
\hline $\begin{array}{l}\text { Butir } \\
\text { Pertanyaan }\end{array}$ & $\begin{array}{l}\text { Hitung } \\
\text { Tabel }\end{array}$ & $\begin{array}{l}\text { r } \\
\text { Teterangan }\end{array}$ \\
\hline Y1 & 0,947 & 0,195 & Valid \\
\hline Y2 & 0,880 & 0,195 & Valid \\
\hline
\end{tabular}

Uji Reliabilitas

$\begin{array}{llll}\text { Tabel } & 1.6 & \text { Hasil } & \text { Uji }\end{array}$

Reliabilitas

\begin{tabular}{|l|c|c|c|}
\hline \multicolumn{1}{|c|}{ Item } & $\begin{array}{c}\text { Cronbach's } \\
\text { Alpha }\end{array}$ & Reliabilitas & Keterangan \\
\hline Harga $(\mathrm{X} 1)$ & 0,920 & 0,60 & Reliabel \\
\hline Promosi $(\mathrm{X} 2)$ & 0,912 & 0,60 & Reliabel \\
\hline Bukti Fisik $(\mathrm{X} 3)$ & 0,800 & 0,60 & Reliabel \\
\hline Kualitas Layanan $(\mathrm{X} 4)$ & 0,931 & 0,60 & Reliabel \\
\hline Minat Berkuniung(Y) & 0,925 & 0,60 & Reliabel \\
\hline
\end{tabular}

Berdasarkan tabel 1.6 menujukan bahwa nilai Cronbach's Alpha lebih besar dari 0,60. Dengan demikian dapat disimpulkan bahwa alat ukur yang digunakan dalam penelitian ini adalah reliabel.
Uji Asumsi Klasik

Uji Normalitas

Gambar 1.2 Diagram Uji Normalitas

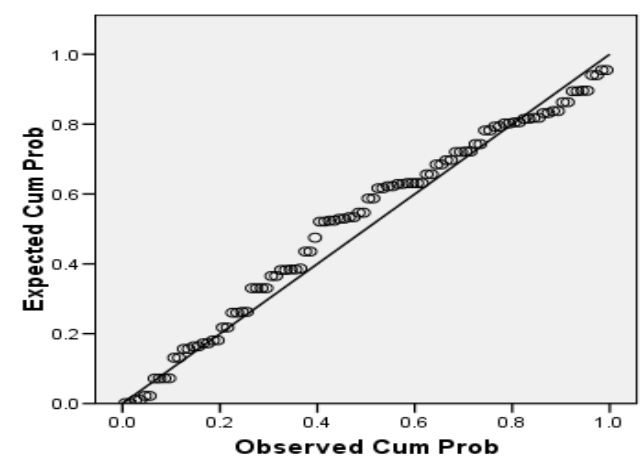

Dari gambar 1.2 dapat diketahui bahwa PP plot standardized residual menunjukan titik-titik menyebar di sekitar garis dan mengikuti garis diagonal yang juga menunjukan pola data berdistribusi normal. Berdasarkan hal tersebut maka disimpulkan bahwa data distribusi normal.

Uji Multikolinearitas

Tabel 1.7 Koefisien Tolerance Value Dan VIF Masing-Masing Variabel

\begin{tabular}{|l|l|l|l|}
\hline Variabel Bebas & $\begin{array}{l}\text { Tolera } \\
\text { nce } \\
\text { Value }\end{array}$ & $\begin{array}{l}\text { VI } \\
\text { F }\end{array}$ & Keterangan \\
\hline Harga (X1) & 0,906 & $\begin{array}{l}1,1 \\
04\end{array}$ & $\begin{array}{l}\text { Nonmultikoli } \\
\text { nieritas }\end{array}$ \\
\hline Promosi (X2) & 0,543 & $\begin{array}{l}1,8 \\
04\end{array}$ & $\begin{array}{l}\text { Nonmultikoli } \\
\text { nieritas }\end{array}$ \\
\hline Bukti Fisik (X3) & 0,506 & $\begin{array}{l}1,9 \\
77\end{array}$ & $\begin{array}{l}\text { Nonmultikoli } \\
\text { nieritas }\end{array}$ \\
\hline $\begin{array}{l}\text { Kualitas } \\
\text { Layanan (X4) }\end{array}$ & 0,987 & $\begin{array}{l}1,0 \\
14\end{array}$ & $\begin{array}{l}\text { Nonmultikoli } \\
\text { nieritas }\end{array}$ \\
\hline
\end{tabular}

Berdasarkan tabel 1.7 hasil uji multikolinearitas di atas, dapat diketahui bahwa nilai Tolerance Value dan VIF dari variabel bebas adalah lebih besar 0,10 dan lebih kecil dari 10 dan dinyatakan tidak terjadi gejala multikolinearitas dalam perasamaan regresi, sehingga dapat disimpulkan bahwa uji multikolinearitas terpenuhi.

Uji Autokorelasi

Tabel 1.8 Nilai Durbin Watson

\begin{tabular}{|l|l|l|}
\hline & Nilai & Keterangan \\
\hline $\begin{array}{l}\text { Durbin } \\
\text { Watson }\end{array}$ & $\mathbf{2 , 1 0 2}$ & $\begin{array}{l}\text { Tidak ada } \\
\text { autokorelasi }\end{array}$ \\
\hline
\end{tabular}

Berdasarkan tabel 1.8 diatas menunjukkan bahwa nilai Durbin Watson 2,102 terletak antara batas atas du (1,76) dan 4-du (2,24). Berdasarkan kriteria $\mathrm{du} \leq \mathrm{d} \leq 4-\mathrm{dL}$ maka $(1,76$ 
$<2,102<2,24)$. Maka dapat di simpulkan tidak terdapat autokorelasi pada model regresi ini.

\section{Uji Heteroskedastisitas}

Gambar 1.3

\section{Hasil Uji Heterokedastisitas}

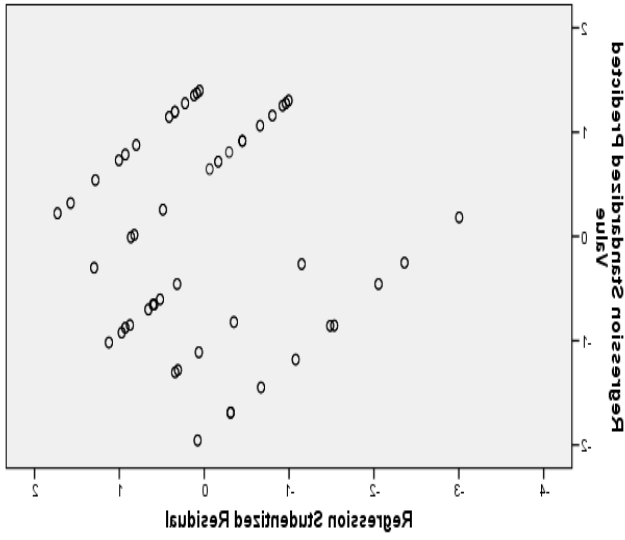

Berdasarkan gambar 1.3 dapat diketahui bahwa plots menyebar di kanan dan kiri angka 0 pada sumbu $\mathrm{x}$ atas serta di bawah angka 0 pada sumbu y. Sehingga dapat disimpulkan bahwa uji heterokedastisitas tidak terpenuhi.

Uji Regresi Linear Berganda Analisis Regresi Linier Berganda $\mathrm{Y}=-2,070+0,117 \mathrm{X} 1+0,709 \mathrm{X} 2+0,664 \mathrm{X} 3$ $+0,144 \mathrm{X} 4+\mathrm{e}$

Tabel 1.9

\begin{tabular}{|c|c|c|c|c|c|c|}
\hline \multicolumn{2}{|c|}{ Model } & \multicolumn{2}{|c|}{$\begin{array}{l}\text { Unstandardized } \\
\text { Coefficients }\end{array}$} & \multirow{2}{*}{ 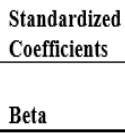 } & \multirow[b]{2}{*}{$t$} & \multirow[b]{2}{*}{ Sig. } \\
\hline & & B & Std. Error & & & \\
\hline \multirow[t]{5}{*}{1} & (Constant) & -2.070 & .556 & & -3.720 & .000 \\
\hline & Harga & .117 & .069 & .104 & 1.683 & .096 \\
\hline & Promosi & .709 & .097 & .584 & 7.300 & .000 \\
\hline & Bukti Fisik & .664 & .211 & .261 & 3.153 & .002 \\
\hline & Kualitas Layanan & .144 & .063 & .137 & 2.302 & .024 \\
\hline
\end{tabular}

Koefisien Determinasi $\left(\mathbf{R}^{2}\right)$

Tabel 1.10 Hasil Koefisien Determinasi $\left(\mathbf{R}^{2}\right)$

\begin{tabular}{|c|c|c|c|c|}
\hline & $\mathbf{R}$ & $\begin{array}{l}\mathbf{R} \\
\text { Square }\end{array}$ & $\begin{array}{l}\text { Adjuste } \\
\text { d } \quad \text { R } \\
\text { Square }\end{array}$ & $\begin{array}{l}\text { Std. } \\
\text { Error of } \\
\text { the } \\
\text { Estimate }\end{array}$ \\
\hline 1 & $.818(a)$ & .670 & .656 & .42929 \\
\hline
\end{tabular}

1. Dilihat dari tabel 4.21, hasil Adjusted R Square $=0,656$ dapat dikatakan perubahan variabel dependen Minat Berkunjung (Y) sebesar $65,5 \%$ disebabkan oleh variabel Harga (X1) , Promosi (X2) , Bukti Fisik (X3) , Kualitas Layanan (X4), sedangkan
$34,4 \%$ disebebkan oleh faktor lain yang tidak ada dalam model ini.

2. $\mathrm{R}$ squere sebesar 0,670 artinya variabel terhadap variabel Harga (X1), Promosi (X2), Bukti Fisik (X3), Kualitas Layanan (X4) mampu menjelaskan variabel Minat Berkunjung (Y) sebesar $67 \%$ sisanya sebesar 33\% disebabkan oleh faktor lain yang tidak ada dalam model ini.

3. R 0,818 artinya kuatnya hubungan antar variabel independen (X) bersama-sama terhadap variabel $(\mathrm{Y})$ yaitu $8,18 \%$.

\section{Uji Hipotesis}

Uji Parsial (Uji t)

Tabel 1.11 Hasil Uji Parsial (Uji t)

\begin{tabular}{|c|c|c|c|c|c|c|c|c|}
\hline \multicolumn{9}{|c|}{ Coefficients ${ }^{2}$} \\
\hline \multirow[b]{2}{*}{ Model } & & \multicolumn{2}{|c|}{$\begin{array}{l}\text { Unsiandarcized } \\
\text { Coefficients }\end{array}$} & \multirow{2}{*}{$\begin{array}{c}\text { Standaroized } \\
\text { Coefficients } \\
\text { Beta }\end{array}$} & \multirow[b]{2}{*}{$t$} & \multirow[b]{2}{*}{ Sig. } & \multicolumn{2}{|c|}{ Collinearity Statistics } \\
\hline & & B & Sto. Error & & & & Tolerance & VF \\
\hline 1 & (Constant) & $-2,070$ & .556 & & $-3,720$ & .000 & & \\
\hline & Harga & 117 & ,069 & 104 & 1,683 & , 096 &, 906 & 1,104 \\
\hline & Promosi &, 709 & 097 & .584 & 7,300 & .000 & .543 & 1,840 \\
\hline & Bukti_Fisik & .664 & .211 & .261 & 3,153 & .002 & .506 & 1,977 \\
\hline & Kualitis__Layanan & 144 & ,063 & 137 & 2,302 & ,024 & .987 & 1,014 \\
\hline
\end{tabular}

Uji Simultan (Uji F)

Tabel 1.12 Hasil Uji Simultan (Uji F)

\begin{tabular}{|c|c|c|c|c|c|c|}
\hline Model & & $\begin{array}{l}\text { Sum of } \\
\text { Squares }\end{array}$ & df & $\begin{array}{l}\text { Mean } \\
\text { Square }\end{array}$ & $\mathrm{F}$ & Sig. \\
\hline \multirow[t]{3}{*}{1} & Regression & 35,533 & 4 & 8,883 & 48,203 &, $000(a)$ \\
\hline & Residual & 17,507 & 95 & , 184 & & \\
\hline & Total & 53,040 & 99 & & & \\
\hline
\end{tabular}

Pada $F$ tabel didapat angka sebesar 2,70. Ini berarti $\mathrm{F}$ hitung > F tabel $(48,203>2,70)$. Maka H0 ditolak dan H1 diterima dapat diartikan bahwa variabel Harga (X1), Promosi (X2), Bukti Fisik (X3), dan Kualitas Layanan (X4) secara bersama-sama (simultan) berpengaruh terhadap minat berkunjung.

\section{SIMPULAN DAN SARAN}

Berdasarkan hasil pengolahan data dalam penelitian ini dapat ditarik kesimpulan sebagai berikut :

1. Harga tidak mempunyai pengaruh secara parsial terdapat minat berkunjung di Dynasty Water World Gresik. Semakin tinggi harga yang ditetapkan maka semakin sedikit minat berkunjung.

2. Promosi mempunyai pengaruh signifikan secara parsial terhadap minat berkunjung di Dynasty Water World Gresik. Semakin sering melakukan promosi, maka semakin banyak/meningkat pula minat berkunjung di Dynasty Water World Gresik.

3. Bukti Fisik mempunyai pengaruh signifikan secara parsial terhadap minat 
berkunjung di Dynasty Water World Gresik. Semakin baik kondisi fisik sebuah tempat, maka semakin banyak/meningkat pula minat berkunjung di Dynasty Water World Gresik.

4. Kualitas Layanan mempunyai pengaruh signifikan secara parsial terhadap minat berkunjung di Dynasty Water World Gresik. Semakin baik kualitas yang diberikan penyedia jasa, maka semakin meningkat pula minat berkunjung di Dynasty Water World Gresik.

5. Hasil uji hipotesis melalui uji simultan (F) menyatakan bahwa harga, promosi, bukti fisik, dan kualitas layanan mempunyai pengaruh signifikan secara simultan terhadap minat berkunjung di Dynasty Water World Gresik.

Berdasarkan hasil analisis, pembahasan dan kesimpulan penelitian, maka saran-saran dari peneliti yang dapat diberikan adalah sebagai berikut :

Bagi perusahaan :

1. Harga : Pihak manajemen Dynasty Water World Gresik agar terus meningkatkan usaha agar memperoleh keuntungan yang diharapkan dan memperhatikan perbandingan harga dengan pesaing, kemudian memberikan harga khusus sebagai harga promosi, serta tetap mengupayakan agar harga yang ditetapkan dapat terjangkau oleh konsumen. Karena penelitian ini membuktikan bahwa Semakin tinggi harga yang ditetapkan maka semakin sedikit minat berkunjung.

2. Promosi : Pihak manajemen Dynasty Water World Gresik juga diharapkan dapat melakukan aktivitas promosi yang lebih baik melalui media cetak,elektronik,ataupun program-program promosi lainnya, sehingga melalui media sosial yang saat ini sedang booming. Semakin sering melakukan promosi, maka semakin banyak/meningkat pula minat berkunjung di Dynasty Water World Gresik.

3. Bukti Fisik : Dari aspek lingkungan, pihak manajemen Dynasty Water World Gresik diharapkan dapat meningkatkan kenyamanan, ketersediaan infrastruktur pendukung dan penerangan yang memadai, karena hasil penelitian ini membukikan . Semakin baik kondisi fisik sebuah tempat, maka semakin banyak/meningkat pula minat berkunjung di Dynasty Water World Gresik.

4. Kualitas Layanan : Pihak manajemen Dynasty Water World Gresik juga diharapkan dapat meningkatkan kualitas layanan bagi pengunjungnya, karena hasil penelitian ini mampu membuktikan bahwa Semakin baik kualitas yang diberikan penyedia jasa, maka semakin meningkat pula minat berkunjung di Dynasty Water World Gresik.

\section{DAFTAR PUSTAKA}

Alma. 2013. Manajemen Pemasaran dan pemasaran Jasa. Bandung. Alfabeta.

Engel, F. James; Roger D. Blackwell; Paul W. Miniard. 2008. Perilaku Konsumen. Jakarta: Binarupa Aksara.

Ghozali, Imam. 2013. "Aplikasi Analisis Multivariate dengan Program SPSS". Semarang : Badan Penerbit Undip.

Helmawati, Triana dan Handayani, Siti D. 2013. Pengaruh Kualitas Layanan Terhadap Minat Kunjungan Ulang Yang Dimediasi Oleh Kepuasan Pasien Di Klinik Rumah Zakat Yogyakarta. Universitas Muhammadiyah Yogyakarta.

Hurriyati, Ratih. 2005. Bauran Pemasaran dan Loyalitas Konsumen. Bandung CV. Alvabeta.

Kotler, Phiplip \& Gary Amstrong. 2014. Prinsip-prinsip pemasaran. Edisi 15. Jilid I. Penerbit Erlangga. Jakarta.

Kotler, P dan Keller, K.L. 2013. Manajemen Pemasaran. Jilid Ke 1. Edisi 13 Jakarta : Erlangga

Nur, Indriantoro dan Bambang Supomo. 2014. Metodologi Penelitian Bisnis. Yogyakarta: BPFE

Ramanda, Siti Meutia. 2013. Pengaruh People, Process, dan Physical Evidence Terhadap Kepuasan Konsumen Pada PT Elnusa Petrofin Padang. Universitas Tamansiswa Padang

Saradisa, Catrina Nora. 2012. Pengaruh Harga, Promosi, Lokasi, dan kualitas Layanan terhadap Kepuasan Pelanggan. Jurnal Ilmu dan Riset Manajemen Volume 4, Nomor 11, November 2015. Sekolah Tinggi Ilmu Ekonomi Indonesia (STIESIA)

Swastha, Basu dan T Hani Handoko. 2014. Manajemen Pemasaran (Analisis Perilaku Konsumen). BPFE. Yogyakarta.

Tjiptono, Fandy. 2011. Strategi Pemasaran. Edisi kedua.Penerbit Andi Offset. Yogyakarta. 
Tjiptono, Fandy. 2012. Pemasaran Jasa. Bayu Media Publishing. Yogyakarta.

Widyanti, Arti. 2015. Analisis Kualitas

Layanan, Harga, dan Lokasi

Terhadap Keputusan Pembelian di

Kedai CS Warung Kopi

Mendungan Kartasur. 